mansasa

glyndwhr

Glyndŵr University

Glyndŵr University Research Online

Social Inclusion Research Unit

Social and Community

$1-1-2002$

\title{
From Kama Sutra to dot.com- The History, Myths and Management of Premature Ejaculation
}

Edna M. Astbury-Ward

Glyndwr University, e.astbury-ward@chester.ac.uk

Follow this and additional works at: http://epubs.glyndwr.ac.uk/siru

Part of the Family Practice Nursing Commons, Gender and Sexuality Commons, Medicine and Health Commons, Other Nursing Commons, and the Public Health and Community Nursing Commons

Copyright (C) 2002 Routledge Taylor and Francis. This is an electronic version of an article published in Astbury-Ward, E. (2002) 'From Kama Sutra to dot.com- The History, Myths and Management of Premature Ejaculation. Journal of the British Association for Sexual and Relationship Therapy.

17(4),367-379. The published version is available online at http://www.tandfonline.com/doi/abs/ $10.1080 / 1468199021000017218$

\section{Recommended Citation}

Astbury-Ward, E. (2002) 'From Kama Sutra to dot.com- The History, Myths and Management of Premature Ejaculation'. Journal of the British Association for Sexual and Relationship Therapy. 17(4),367-379

This Article is brought to you for free and open access by the Social and Community at Glyndŵr University Research Online. It has been accepted for inclusion in Social Inclusion Research Unit by an authorized administrator of Glyndŵr University Research Online. For more information, please 


\section{The History, Myths and Management of}

\section{Premature Ejaculation}

\section{Introduction}

As long as man has breathed, his fascination, pursuit and quest for the perfect sexual experience have remained one of his principal raison d'être. After thousands of years, millions of words and pictures, and billions of attempts, he still finds the goal chiefly unobtainable. How have we arrived where we are today? Modern understanding of premature ejaculation $(\mathrm{PE})$ is an eclectic mix, and homogenisation of ancient historical and culturally diverse influences. By analysing the past it is possible to gain a better appreciation of how the problem is perceived and managed today.

This essay will look at some of those influences throughout history and culture. It will focus on references to PE and it's treatment. The essay will conclude with an overview of current awareness and modern therapies and treatment options.

\section{The Historical Perspective}

The Bible states that semen was intended to be deposited only in vaginas and mainly for the purpose of procreation. Men were told: "Be fruitful, and multiply and replenish the earth" (Genesis 2). The punishment for not obeying God's Law was death, as Onan was to discover to 
his peril. Onan's father, Judah, forced him to marry his brother's widow Tamar, whom he did not love. Onan discovered that during coitus he could not ejaculate into Tamar "he spilled it (semen) on the ground, and the thing which he did displeased the Lord: wherefore He slew him" (Genesis 38). The word 'Onanism' has become associated with the "withdrawal of the penis from the vagina before ejaculation, or masturbation" (Collins Dictionary 1982). The Bible was not the only major work that influenced society in matters of love. In other cultures and times, there were many references to the importance of ejaculation and the art of love and sexuality (ars erotica).

The Indian god Shiva, who has the power to destroy and create, is often represented with an erect phallus, a symbol of power and fertility. Because Shiva always holds back his seed, the 'lingam' (penis) remains erect, as a potential creator (Mattelaer 2000). Semen is considered to be a precious substance in Indian cultures (Gupta 1999) and many myths have been created around it. Atharva-ved, one of the ancient Indian religious books mentions that 100 drops of blood are required to make one drop of semen. Loss of semen was considered then (and still is) as a loss of strength. Male weakness caused by a loss of semen is called 'mardana-kamzori' (Gupta 1999); this and PE is collectively known as 'Dhat syndrome' (Bhatia and Malik 1991).

The Kama Sutra (The Melody of Love) was written between the $1^{\text {st }}$ and $4^{\text {th }}$ centuries A.D. by Mallanaga, a bachelor belonging to the Vatsyayana sept. It can be described as a lifestyle book of its era. As a book devoted to personal discipline, it offered amongst other things a range of knowledge that the reader may acquire, to find (and keep) a partner. It gave suggestions on many subjects, from how to freshen the breath by chewing betel leaves to a range of sexual positions that "seems often to be addressed to a contortionist" (Burton and Arbuthnot 1963). It was first published in Britain in 1876, but was considered by Victorian England to be far too 
lewd and was not officially available until 1963 . The 1963 version was dedicated "To that small portion of the British public which takes enlightened interest in studying the manners and customs of the olden East".

Part Two of the Kama Sutra deals exclusively with sexual union and considers different lengths of time to ejaculation as having various merits. The author believes that "The first time of union the passion of the man is intense, but on subsequent union the reverse of this is true." He says that "if a male be long-timed, the female loves him the more, but if he be short timed, she is dissatisfied with him." He concludes "that males when engaged in coition, cease of themselves after emission and are satisfied, but it is not so with females."

This is a clear reference to the fact that PE causes frustration and friction. It highlights the differences in needs and desires between men and women; no wonder it was considered too dangerous to be read by Victorian women.

China's association with sexology can be traced back many dynasties. The Tang Dynasty (618907 A.D.) was considered to be sexually free, and during this period sex was positively encouraged as the means to good health. Early Taoist philosophers saw frequent and longlasting sex as promoting balance between the Yin (negative, dark, feminine) and Yang (positive, bright, masculine). Sex was considered the very essence of nature and harmony. It was also thought that to ejaculate ('chi') made the man weak for the next sexual encounter. Delaying or suppressing ejaculation was felt to be beneficial, and a disciplined approach to delaying ejaculation became popular (Tantra/Yoga).

In the Ming Dynasty (1368-1644), attitudes to sex became more restricted, and by the Quing Dynasty (1644-1911), sexuality was repressed and regulated. "The eighteenth century 
witnessed profound change in imperial law: the basic organising principle for the regulation of sexuality shifted away from status (were it had long been held) to standards of familial and sexual morality" (Sommer and Harvey 2000).

Sixteenth century Islamic Tunisia had its own version of the Kama Sutra. Its book on the art of love was called The Perfumed Garden, written by Sheikh Nefzawi, adviser to the Grand Vizar of Tunis. He makes specific reference to PE, but offers no remedy for the problem. "When the mutual operation is performed, a lively combat ensues between the two actors who frolic and kiss and intertwine. Man in the pride of his strength, works like a pestle, and the woman, with lascivious undulations, comes artfully to his aid. Soon all too soon the ejaculation comes!" (Nefzawi)

Erotic life flourished at all levels of society in ancient Egypt (Shokier and Hussein 1999). Life, the afterlife, fertility and creation are important parts of Egyptian history, and representations of such can be seen on many temple carvings and paintings. Of particular interest were the remedies that the ancient Egyptians considered useful for various sexual ailments and problems. The lotus flower was an important icon in ancient Egypt (von Baeyer 2000). It is endowed with an exotic aura and magical allure (von Baeyer 2000) Magical properties have been associated with the lotus flower since it arose at the beginning of time from the waters of Nun (the original waters) (Mattelaer 2000). It was immortalised in modern times when lotus and cornflowers were discovered in the coffin of Tut-Ankh-Amon (Time-Life 1992). At the first ray of the sun, the lotus flower opens up and releases a hyacinth like scent. When an Egyptian buried his nose in a lotus flower and kept it there for a while, the effect on him may have been considerable, and the scent may have been sufficient to achieve an alteration in consciousness 
(Manniche 2001) this may have had the effect of reducing anxiety and possibly delaying ejaculation, although there is no specific mention of PE.

\section{The Twentieth Century}

Dr. Marie Stopes in her revolutionary book, Married Love (1917), which is dedicated to "young husbands and all those who are betrothed in love", gives advice in the chapter, Mutual Adjustment, it is said, "men's mental and physical stimulation reaches a climax in sensory intoxication and the ejaculation of semen." Stopes mentions the possibility of a simultaneous orgasm: "Where the two are perfectly adjusted, the woman simultaneously reaches the crisis of nervous and muscular reactions very similar to his". She notes that often this is not a reality, "but in many cases the man's climax comes so swiftly that the woman's reactions are not nearly ready, and she is left without it." She estimates that as many as $70-80 \%$ of women are anorgasmic during intercourse (although this seems a high estimate) and are "deprived of the full orgasm through the excessive speed of the husband's reactions". Stopes puts an actual time on the average length of intercourse: "two or three minutes often completes the union for a man who is ignorant of the need to control his reactions".

However Stopes does not provide any scientific evidence for these facts and figures. According to Stopes, the point of inevitable ejaculation occurs when the man is so "stimulated that the ejaculation has become involuntary". Interestingly, Stopes offers no help to the man who suffers with PE, but she does explain at length how the man may bring his wife to orgasm through stimulation of the clitoris. She describes in detail the function and location of the clitoris. 
When Kinsey et al wrote Sexual Behaviour in the Human Male in 1948, it was considered to be the new bible on sexuality, and is quoted widely in the medical and associated literature. Recently some doubt has been cast on the book's findings. Given the vast number of subjects interviewed, there is speculation that the research could not have been completed within the reported time frame. Kinsey stated in 1948 that $75 \%$ of men ejaculate within two minutes of intromission

Ejaculation and the sexual act remains a subject of fascination, observation and research. We seem to have moved away from the 'Ars erotica' era, “where truth was drawn from pleasure itself, understood as a practice and accumulated as an experience" (Foucault 1976), and into the 'Scientia sexualis' era, characterised by the growth of contemporary forms of disciplinary knowledge of sex - a type of 'sanitised science' involving a search for the disciplinary 'truth'. This type of discipline originally emerged in Western societies during the Victorian era (Pryce 2001). It replaced the 'ars erotica' period, and according to Foucault, "there emerged a completely new technology of sex through the institution of medicine especially". Foucault argued that this form of investigation was concerned with rational sexualities, health and disease, safer sex and the regulation of people's bodies, but this discipline also took pleasure in its own work. He believes 'Scientia sexualis' involves "pleasure in the truth of pleasure, the pleasure of knowing that truth, of discovering and exposing it, the fascination of seeing it and telling it, and confiding in its secrets".

PE continues to generate discussion and argument today. The term PE, often referred to as rapid ejaculation (Riley 1995), is a problem that concerns control and timing of ejaculation (Roblin 2000). That much is agreed. According to Athanasiadis (1998), "To date there is no universally accepted definition of PE." Athanasiadis considers that this is probably "a 
reflection of existing confusion over the aetiology and clinical expression of the condition". Eardley and Sethia (1998) have similar views, but offer no explanation for their opinions. Vale (1999) also agrees with Athanasiadis, and argues that "as a diagnosis, it (PE) is fraught with confusion and even its definition has been the subject of debate". Vale adds to the confusion by defining PE in his own words: "an inability to exert voluntary control over ejaculation such that, once aroused, orgasm is reached rapidly, leading to dissatisfaction with the sexual act for both partners". Many other such self-styled definitions can be found in the literature.

Definitions have been based on a number of parameters, including ejaculatory latency, number of thrusts, partner satisfaction and voluntary control (Athanasiadis 1998).

The Diagnostic and Statistical Manual of Mental Disorders (American Psychiatric Association, 1994) defines PE as "persistent or recurrent ejaculation with minimal sexual stimulation before, on, or shortly after penetration and before the person wishes it... Furthermore, the disturbance causes marked distress or interpersonal difficulty, and it is not due exclusively to the direct physiological effects of a substance."

The ICD-10: DCR-10 (1994) defines PE as "an inability to delay ejaculation sufficiently to enjoy lovemaking, manifest as either of the following: (1) occurrence of ejaculation before or very soon after the beginning of intercourse (if a time limit is required: before or within 15 seconds of the beginning of intercourse); (2) ejaculation occurs in the absence of sufficient erection to make intercourse possible. The problem is not the result of prolonged abstinence from sexual activity." In practice the use of The Diagnostic and Statistical Manual of Mental Disorders (American Psychiatric Association, 1994) use of the words, distress and difficulty may help practitioners with a diagnosis. 
However, there are also difficulties with these definitions. What one person may consider being "minimal sexual stimulation", another person may not. What exactly does "shortly after" mean? Does a man who has three hours' foreplay and then ejaculates "very soon after" penetration, have PE? What if a person "wishes" intercourse to last three days, but ejaculates after "only" one hour?

Ejaculatory latency was considered to be a good measure of PE, and much data have been generated on this subject alone. Kinsey stated in 1948 that $75 \%$ of men ejaculate within two minutes of intromission, and he was in agreement on this point with Stopes (1917) and Hite (1981). Some authors consider that if ejaculation occurs within 15 seconds of penetration, it can be considered premature (Athanasiadis 1998, Roblin 2000), as judged by ICD-10. Roblin believes the ICD-10 definition is superior to that of DSM IV, which he finds "non specific and vague". He considers the advantage of ICD-10 to be that it "defines latency time post intromission", but others do not agree and the argument continues.

Prevalence is also part of the PE debate, and the following quotes have been made about this topic:

"There is limited information concerning the extent of PE in the general population" (Roblin 2000) "High prevalence across all socio-economic groups" (Butcher 1993) "Highly prevalent though under-reported” (Lane 1997) “Common problem' (Athanasiadis 1998, Gupta 1999) "Commonest form of male sexual dysfunction" (Vale 1999) “21\%” (Laumann et al 1999) "22\%-38\%" (Roblin 2000) 35\% (Nathan 1986), as quoted by (Lane 1997) 36\% (Frank et al 1978) "almost 40\% on a recurring basis" (Riley 2000) "40\% ongoing problem" (Nettelbladt and Uddenberg 1979) “1\%-75\%" (Metz \& Pryor 2000) “75\%” (Kinsey et al 1948, 
Athanasiadis 1998) It is apparent that PE is a significant problem for many men at some point in their lives, but the figures are inconsistent and may not reflect the true incidence of the problem.

\section{Anatomy and Physiology}

The three phases of orgasm are emission, closure and ejaculation. The structures involved include the vasa deferentia, the ejaculatory ducts and seminal vesicles, the bladder neck and prostate, and the muscles of the perineal floor. Embryologically, the vas deferens is derived from the Woolfian ductal system. The vas deferens is innervated with adrenergic nerves. The ejaculatory duct is formed where the ampulla of the vas and the seminal vesicle join at the base of the prostate, where it opens as a slit on the verumontanum. The ejaculatory duct conveys semen from the ampulla of the vas, which has some storage capacity, to the prostatic urethra. The seminal vesicles contain very little smooth muscle, and do not contract very much during the ejaculatory process (Vale 1999). The seminal vesicles do not store sperm, but produce and store secretions that are added to sperm. The role of the bladder neck is to close in normal ejaculatory function. The bladder neck contracts in response to noradrenaline via stimulation of $\alpha 1$-adrenoceptors.

Ejaculation is the passage of seminal fluid through the urethra, and expulsion of the fluid via the external urethral meatus by rhythmic contractions of the prostate gland, seminal vesicles and muscles of the perineal floor, particularly the bulbocavernous and ischio-cavernous muscles. Other events that occur at this time are closure of the internal sphincter of the bladder (to prevent retrograde ejaculation). Ejaculation then occurs with relaxation of the external sphincter. This event is also called orgasm and is usually associated with pleasurable 
sensations and release of sexual tension. On very rare occasions, this event has been associated with genital pain (Kaplan 1993). Kaplan thought this pain was nearly always psychogenic in origin, but also said that certain urological conditions (prostatitis and urethritis) need to be ruled out before making the diagnosis.

The causes of PE are numerous, but can be grouped into two main categories: physical and psychological (Butcher 1993). Athanasiadis (1998) considers that none of the proposed biogenic or non-biogenic theories offer a satisfactory explanation.

As late as the 1940s, PE was considered to be related to abnormalities of the verumontanum, and cauterisation of the verumontanum was recommended as a treatment (Vale 1999). Several illnesses and injuries may contribute to PE. Most of the physiological causes can be attributable to urological disorders and diseases of the local genitourinary tract. These include prostatic hypertrophy, prostatitis and urethritis. Other generalised conditions that may also contribute are arteriosclerosis, diabetes, polyneuritis and neurological disease (Athanasiadis 1998). Pelvic fractures and surgical trauma may also lead to PE.

The evolutionists consider that PE is biologically predisposed. Metz \& Pryor (2000) believed that rapid ejaculation is normal and biologically rooted in evolution; this was also one of Kinsey's (1948) theories. Cartwright (2000) considered that men who ejaculated quickly were at a biological advantage, and rapid ejaculation was believed to be the best option in case of danger. Hong (1994), as quoted by Athanasiadis (1998), considered quick copulation to be a superior reproductive strategy, but Athanasiadis (1998) argues that this theory does not fit "with the extended foreplay and courting behaviours demonstrated in several species." 
Xin et al $(1994,1995,1996,1997 \& 2000)$ maintains that penile hypersensitivity is a physical cause, and has gone to great lengths to prove the point. According to Rowland, results of a trial of 26 men with PE indicated that 'Psychophysiological testing indicated greater ejaculatory vulnerability to penile stimulation' than in the functional control group (Rowland et al 2000). This study is in complete contrast to Rowland et al's (1993) earlier study, in which they found that men with PE did not present greater penile hypersensitivity. Vale (1999) suggests that the patient's perception of penile hypersensitivity contributes to the PE, and he considers this to be centrally mediated, but Roblin (2000) argues, "the glans penis has touch receptors that are connected via the dorsal, penile and pudendal nerve to the sacral spinal cord. How cortical activation reaches the ejaculatory-related systems is not known."

The nerve receptor density of the glans penis is higher than any other part of the body and has a high tactile threshold (Eardley \& Sethia 1998), and therefore is more sensitive than most other parts of the body (Astbury-Ward 2000). Eardley and Sethia (1998) believe the threshold of sensation may alter with changing temperatures, as might be encountered with penetration. Could this be one of the reasons that ejaculation occurs within seconds of penetration? Athanasiadis (1998) summed up these differences, when he wrote that: "Studies on the role of penile sensitivity have shown conflicting results."

The bulbocavernous reflex (BCR) has also been studied as a possible physical cause of PE, and it has been suggested that the response to bulbocavernosal stimulation is higher in those with PE than the control group (Vale 1999). Metz and Pryor (2000) think this suggests that some men with lifelong PE possess a generalised neurologic or biological susceptibility to fast ejaculation. They recommend neurological examination in the case of patients with 
lifelong/severe PE to establish the integrity of the sacral reflex arc. However, norms for tests of BCR have not been sufficiently established to use them routinely.

\section{Aetiology and Psychosocial Influences}

The evidence for organic disease as a basis for PE is largely anecdotal.

Masters and Johnson (1970) believed early sexual experiences are important in the shaping of future ejaculatory habits. They thought that because of initial nervousness and haste, unsatisfactory early sexual experiences would 'programme' a pattern of learned rapid ejaculation later on (a form of negative conditioning). Other authors cite inappropriate venues e.g., backseats of cars, fear of discovery and one-night stands - as possible contributory factors to establishing a pattern of rapid ejaculation (Butcher 1993).

Major depression is characterised by a depressed mood or the inability to experience normally pleasurable activities (American Psychiatric Association 2000). It is clear from this definition how depression affects the individual's enjoyment of sex, and how it may affect the ejaculation process. It is not always easy to determine whether anxiety and depression are the cause or result of the disorder. Some authors believe high levels of anxiety cause distraction during intercourse, and therefore a lack of awareness of the man's own responses. The inability to focus on his own response suggests a failure to recognise the internal clues that signal the point of ejaculatory inevitability, leading to PE (Zilbergeld 1992). This has also been called 'spectatoring'.

Other major mental health problems that may contribute to PE are personality disorders, bipolar depression (a mood disorder where a patient may exhibit separate periods of both 
depression and mania, Gelder et al 1999), obsessive-compulsive disorder and any of the generalised anxiety states.

Some researchers claim that common psychological traits exist among men with PE, but psychological studies do not yield evidence of a common personality profile. In depressed patients, single photon emission computed tomography (SPECT) scans are used to map cerebral blood flow. SPECT has demonstrated reduced flow in areas of the frontal lobe (drive and motivation) and the limbic system (emotions and behaviour) (Martin 2001). This evidence may show an organic association between depression and the inability to experience or perceive normal emotional behaviour. It is recommended by Metz and Pryor that a patient's psychological state be evaluated to determine the degree to which it is influencing ejaculatory patterns, and they consider that PE rooted in such chronic character disorders is more resistant to treatment than distress caused by psychosocial factors (Metz and Pryor 2000).

PE caused by psychosocial factors may be transitory, lasting only as long as the events which influence the man, but they may also become lifelong-acquired as a result of learned behaviour during that period.

Psychosocial events that may contribute to PE include: partner illness, occupational stress, financial stress, shift work, family problems e.g. elderly relatives, bereavement, children, lack of experience or opportunity, poor housing, performance anxiety/fear of failure/expectations, sexual orientation, lack of sexual/interpersonal skills.

One of the commonest reasons given for PE is relationship disorders (Metz \& Pryor 2000, Athanasiadis 1998). Some of the components of relationship distress are: sexually demanding partners, unrealistic expectations, discrepant needs and desires in a relationship, marital 
dissatisfaction, lack of communication and trust, and affairs, partners with concomitant sexual dysfunction; and an excessive desire to please a partner. PE caused by relationship distress is usually distinguished by acquired onset, situational occurrence with a partner, and evidence of relationship difficulty (Metz \& Pryor 2000).

\section{Effects and Treatments}

In 1970, Masters and Johnson said that there was no such thing as an uninvolved partner in any marriage in which there is some form of sexual inadequacy (for "marriage", substitute "partnership" for current usage). They felt that continuing dysfunction would lead to stress for both partners, and that it was beneficial for both partners to attend the therapy sessions. They also considered this to be good practice because it helped reduce the portion of "blame".

The effect of PE on the sufferer, his partner and the relationship can be devastating. It may be something that the relationship has endured for a long time, and eventually it might even lead to the breakdown of the relationship. PE can never be blamed in isolation from all other contributory factors mentioned above. It can be difficult to establish whether it is the cause or the symptom of a poor relationship. The man may fear failing and disappointing his partner and frequently blames himself. His partner is afraid to stimulate him because they are fearful of instant ejaculation. The partners may feel unattractive, emotionally abandoned and consider the problem to have been caused by them. This may lead to avoidance of any sexual encounter, thereby making the problem worse, and a relationship already under stress will deteriorate. Blame, anger, criticism, abandonment and rejection are frequent elements of this problem.

Before any type of treatment can be started, it is vital that the correct diagnosis of PE is established by using one of the reliable definitions given earlier and by taking a comprehensive 
medical, social and sexual history. Clear, simple questioning will help. Traditionally, PE was always treated with psychotherapy and sex therapy. Many of these conventional methods are still in use today. Recently there has been increasing interest in the pharmacological treatment of PE, and a number of studies have examined this therapeutic area. The goals of sex therapy need to be considered in terms of the individual and the couple, and these goals need to be discussed with the individual and the couple. Ground rules for the consultation, and an indication of the length of the process, should be given at the start. Any instructions or homework exercises should be given in a clear and concise manner, and ideally should be supported with written instructions and a "contract".

\section{Sensate Focus}

Sensate focus is a programme of exercises designed to reduce performance anxiety and improve the general level of communication between the couple On its own, it is not usually sufficient to relieve the specific symptom of PE (Cooper 1988), although modifications to sensate focus can be used to support the programme.

\section{Stop-Start technique}

The stop/start technique was popularised by Semans (1956), and it includes progressive masturbation training exercises for the man to familiarise himself with the sensual awareness and regulation during heightened arousal. The aim is to teach the man to recognise the point of ejaculation and the immediate moments before ejaculation (the point of ejaculatory inevitability). When the man has learnt to recognise these sensations, he can instruct his partner to stop the stimulation until the ejaculatory sensation has passed. Stimulation can then begin again. These exercises are repeated three or four times until the man allows himself to ejaculate. 
The squeeze technique is a modified stop-start technique pioneered by Masters and Johnson (1970). The partner firmly squeezes the penis where the glans joins the shaft at the moment of inevitable ejaculation. Diagrams and videos are helpful when giving these instructions to patients. A considerable commitment is required from the couple for these techniques to have any chance of success. The above programmes are only suitable in certain circumstances, i.e., where there is a partnership and if this therapy is culturally acceptable. In Asian cultures, masturbation is unacceptable and taboo; replacing the word masturbation with "pleasuring" may help, but century-old cultural beliefs cannot be changed overnight (Gupta 1999). Evidence suggests that traditional sex therapy outcomes for the treatment of PE are initially satisfactory, but most studies are not controlled and the definition of success is often variable. Most patients do not maintain the benefits and relapse is common (Roblin 2000). Long-term outcomes are poor (Riley 2000). Hawton (1988) reported a 75\% relapse rate at three-year follow up.

No pharmacological agents have yet been licensed for the treatment of PE (Roblin 2000). Indications suggest that anti-depressants such as selective serotonin reuptake inhibitors (SSRIs) may be useful in certain cases (Lane 1997, $\mathbf{M}^{\mathrm{c}}$ Mahon \& Touma 1999), especially where the condition is resistant to traditional methods alone or where the patient has a severe psychological component to his PE.

SSRIs have been described as the treatment of choice because they are highly effective in the short term (by slightly increasing ejaculatory latency time), but they require further evaluation (Riley 2000). However there is some evidence to suggest that the benefit of SSRIs extends beyond the period of active treatment (McMahon 1998). They include fluoxetine hydrochloride, paroxetine hydrochloride, and sertraline hydrochloride. A number of studies have investigated the use of SSRIs, but there is no consensus with regard to optimal dosing. Some studies 
suggest that treatment should be given as required 3-4 hours before intercourse (Roblin 2000), and others recommend treatment be given on a chronic long-term basis $\left(\mathrm{M}^{\mathrm{c}}\right.$ Mahon \& Touma 1999). These studies also recommend varying doses. Some men, however, may consider the use of medication as another indication that they cannot control PE themselves. On withdrawal of the drug, ejaculatory latency time (ELT) is almost the same as those subjects on placebo (Lane 1997, Roblin 2000), and ELT returns almost to baseline.

\section{Topical Applications}

The use of topical applications is not a new phenomenon. Over-the-counter preparations of various anaesthetic creams (e.g. Studd 100тм, which contains $10 \%$ lidocaine) have been approved in the U.K. and U.S. and marketed as 'delay sprays'. SS-cream has also been found to be of some therapeutic use (Choi et al 1999). Condoms are always advised when using these preparations to avoid transferring the cream to the partner. Morales (2000) said that the limited nature of the studies so far does not permit a reliable assessment of their efficacy, and recommended further investigation of these drugs with absorption enhancers.

\section{Conclusion}

This essay has considered the historical perspective of PE. The search has revealed some interesting notions about the causes and treatment. Some of the theories are similar to, and influence, our modern understanding of PE. Considering how much our knowledge of other

conditions has improved over the years, however, we do not seem to have kept pace in the area of PE, and there are still relatively few treatment options. Today's researchers are still undecided on the causes of PE, and great debate surrounds the management of the condition. The epidemiology and prognosis have been poorly described in most of the current papers. 
Reviewing the literature has highlighted many different opinions. Most aspects of PE have been studied, and yet we are seemingly no nearer to a conclusion. Estimates of prevalence vary widely, as does opinion on aetiology and treatment. Lack of a universally accepted definition adds to the difficulties of diagnosing and managing PE. The evidence and results of treatment outcomes are often inconsistent. Long- term follow-up successes are in the minority, and there are no standard guidelines for treatment. It is unlikely that future research will provide us with all the answers, and there may be areas of the problem that continue to remain a mystery, especially the pathophysiology.

One area on which most experts agree is that of the effect of PE on the couple. It may be the cause of, or may contribute to, relationship distress. These opinions can be found in the historic literature, as well as in current research. Couples find great difficulty approaching the subject with health care professionals. Provision of services for patients who suffer with PE is at best patchy, and more often it is non-existent. A multidisciplinary team ideally approaches the problem of PE, where the patient can have access to other services that will complement and support the decision-making process. The introduction of pharmacological remedies for PE is positive, but not if it is at the expense of traditional therapies. The ideal is a combined approach implementing both therapies and involving partners whenever appropriate, but whether it will ever become a reality remains to be seen. 


\section{References}

American Psychiatric Association (1994) Diagnostic and statistical manual of mental disorders. $4^{\text {th }}$ edition. Washington D.C.

Astbury-Ward EM (2000) The erectile dysfunction revolution. Nursing Standard. 15 (11) 34- 40.

Athanasiadis L (1998) Premature ejaculation: is it a biogenic or a psychogenic disorder? Sexual and Marital Therapy. 13 (3) 241-255.

Bhatia MS, Malik SC (1991) Dhat Syndrome, a useful diagnostic entity in Indian culture. British Journal of Psychiatry. 159 691-695.

Butcher J (1993) Ejaculatory problems. British Journal of Sexual Medicine. Jan/Feb p.8-10.

Cartwright J (2000) Evolution and Human Behaviour. London, Macmillan Press Ltd.

Choi HK, Xin ZC, Choi YD, et al (1999) Safety and efficacy study with various doses of SS-cream in patients with premature ejaculation in a double blind, randomised, placebo controlled clinical study. Impotence Research, Basic and Clinical Studies 11 (5) 261-264.

Cooper GF (1988) The psychological methods of sex therapy. In: Sex Therapy in Britain Today. Eds: Cole M \& Dryden W. Milton Keynes, Open University Press.

Davies WV (1985) Pocket Egypt. Oxford, J.V Books.

Davies O (1999) Witchcraft, Magic and Culture 1736-1951. Manchester, Manchester University Press.

Eardley I, Sethia K (1998) Erectile Dysfunction - Current Investigation and Management. London, Mosby-Wolfe Communications.

Foucault M (1978) The History of Sexuality. London, Penguin.

Frank E, Anderson C, Rubenstein D (1978) Frequency of sexual dysfunction in 'normal' couples. New England Journal of Medicine 299 111-115.

Gelder M, Gath D, Mayou R, Cowan P (1996) The Oxford Textbook of Psychiatry. Oxford, Oxford University Press. 
Gupta M (1999) An alternative combined approach to the treatment of premature ejaculation in Asian men. Sexual and Marital Therapy. 14 (1) 71-77.

Hawton K (1988) Erectile dysfunction and premature ejaculation. British Journal of Hospital Medicine. 40 428-436.

Hite S (1981) The Hite report on male sexuality. London, Macdonald.

Hong LK (1984) Survival of the fastest: on the origin of premature ejaculation, Journal of Sexual Research. 20 109-122.

ICD-10: DCR-10 (1994) Classification of mental and behavioural disorders diagnostic criteria for research. Edinburgh, Churchill Livingstone.

Kaplan HS (1993) Post ejaculatory pain syndrome. Journal of Sex and Marital Therapy. 19 (2) 91-103.

Kinsey AC, Pomeroy BW, Martin CE (1948) Sexual Behaviour in the Human Male. Philadelphia, Saunders.

Lane RM (1997) A critical review of selective serotonin reuptake inhibitor-related sexual dysfunction; incidence, possible aetiology and implications for management. Journal of Psychopharmacology. 11 (1) 72-82.

Laumann EO, Paik A, Rosen RC (1999) Sexual dysfunction in the United States: prevalence and predictors. JAMA. 281 (6) 537-544.

Manniche L (2001) Sacred Luxuries, Fragrance, Aromatherapy and Cosmetics in Ancient Egypt. New York, Cornell University Press; and London, Opus Publishing Ltd.

Martin E (2001) Using interpersonal psychotherapy. Professional Nurse. 6 (7) 12331236.

Masters WH \& Johnson VE (1970) Human Sexual Inadequacy. Boston, Little Brown.

Mattelaer JJ (2000) The Phallus in Art and Culture. Amsterdam, Historical Committee of the European Association of Urology.

McMahon CG (1998) Treatment of premature ejaculation with Sertraline. Journal of Urology Vol 159 p 1935-1938.

McMahon CG \& Touma K (1999) Treatment of premature ejaculation with paroxetine hydrochloride. International Journal of Impotence Research. 11 (5) 241-246.

Metz ME \& Pryor JL (2000) Premature ejaculation: A psychophysiological approach for assessment and management. Journal of Sex and Marital Therapy. 26 293-320. 
Morales A. (2000) Developmental status of topical therapies for erectile and ejaculatory dysfunction. International Journal of Impotence Research. 12 (supplement 4) s80-s85.

Muirhead-Gold J (Ed.) (1963) The Kama Sutra of Vatsyayana, p. xvii. London, Panther Books.

Nathan SG (1986) The epidemiology of DSM III psychosexual dysfunctions. Journal of Sex and Marital Therapy. 12 267-282.

Nefzawi (16 ${ }^{\text {th }}$ century) The Perfumed Garden. Publisher unknown.

Nettelbladt P \& Uddenberg N (1979) Sexual dysfunction and sexual satisfaction in 58 unmarried Swedish men. Journal of Psychosomatic Research 23 141-147.

Pryce A (2001) 'Some people live out their own snuff movie': knowledge, safer sex and managing desire in the city. Sexual and Relationship Therapy. 16 (1) 15-33.

Roblin D (2000) Premature ejaculation: diagnosis and pharmacotherapy. International Journal of Pharmaceutical Medicine. 14 (6) 313-318.

Rowland DL, Strassberg DS, de Gouveia CA, Slob AK (2000) Ejaculatory latency and control in men with premature ejaculation: an analysis across sexual activities using multiple sources of information. Journal of Psychosomatic Research. 48 (1) 69-77.

Riley AJ (1995) Comment. Urology.1 (4) 91-93.

Riley AJ (2000) Commentary. International Journal of Pharmaceutical Medicine. 14 (6) 309-310.

Semans JH (1956) Premature ejaculation: a new approach. Southern Medical Journal. 49, 353-358.

Shokier AA \& Hussein MI (1999) Historical review - the urology of Pharaonic Egypt. BJU International. 84 755-761.

Sommer B \& Harvey H (2000) Sex, Law and Society in Late Imperial China. San Francisco, Stanford University Press.

Stopes M (1962) Married Love. $29^{\text {th }}$ Edition. London, Hogarth Press.

The Holy Bible. (King James Version) Genesis Chapter 5 Verse 4 Collins, London; Genesis Chapter 1 Verse 28 Collins, London; Genesis Chapter 38 Verses 9 and 10 Collins, London.

Time Life Books (1992). Egypt Land of the Pharaohs - Lost Civilisations. Alexandria, Time Life Books. 
Vale J (1999). Ejaculatory dysfunction. BJU International. 83 557-563

von Baeyer HC (2000). The Lotus Effect. The Sciences (New York Academy of Sciences). 40 (1) 95- 106.

Xin ZC, Seong DH, Choi HK (1994) A double blind clinical trial on SS-cream on premature ejaculation. International Journal of Impotence Research. Supplement 1D73.

Xin ZC, Choi YD, Seong DH, and Choi HK (1995) Sensory evoked potential and effects of SS-cream in premature ejaculation. Yonsei Medical Journal. 36 397-401.

Xin ZC, Chung WS, Choi YD, et al (1996) Penile sensitivity in patients with primary premature ejaculation. Journal of Urology. 156 979-981.

Xin ZC, Choi YD, Rha KH, and Choi HK (1997) Somatosensory evoked potentials in patients with primary premature ejaculation. Journal of Urology. 158 451-455.

Xin ZC, Choi YD, Lee WH, et al. (2000) Penile vibratory threshold changes with various doses of SS-cream in patients with primary premature ejaculation. Yonsei Medical Journal. 41 (1) 29-33.

Total No of Words $\mathbf{- 5 , 5 7 4}$ 
From Kama Sutra to Dot. Com: The History myths and

$\underline{\text { Management of Premature Ejaculation }}$

Edna Astbury-Ward, RGN, Dip HE, Cert Sexual Health

Nurse Therapist

Deeside Community Hospital

Plough Lane

Aston

Deeside

CH5 1XS 
From Kama Sutra to Dot. Com: The History myths and Management of Premature Ejaculation

\section{ABSTRACT}

As long as man has breathed his quest for the perfect sexual experience seems to have eluded him. Often the experience has been brought to an abrupt end by the misery of premature ejaculation. This paper will look at the history, charting the importance of this event throughout the years and across all cultures. It will look at all modern day therapies and will discuss the implications of introducing pharmocotherapy to a problem that has been traditionally treated by sex therapy. 
